\title{
Conceitos operativos nos estudos da performance
}

\section{Resumo}

Este artigo efetua uma introdução aos Estudos da Performance, com a finalidade de introduzir quatro de seus principais conceitos: o drama social, a liminaridade, a communitas e a performatividade. O dramatismo social efetua uma leitura da realidade empregando um vocabulário da teoria teatral: ator, personagem, conflito, cena etc. A liminaridade é a condição intervalar na qual penetra o neófito de um rito de passagem, sendo a communitas um sentimento de grupo que se instala entre eles e Ihes permite um auto reconhecimento. A performatividade é a condição acional da performance, entendida também como virtualidade.

\section{Abstract}

This article highlights an introduction over performance studies with the goal of introducing four of their principal concepts: social drama, liminarity, communitas and performativity. The Social dramatism accomplishes a view of reality utilizing a theatre vocabulary, such as actor, character, conflict, scene etc. Liminarity is the gap condition of a novice in a passage ritual, being communitas the group feeling that they develop as a mutual recognition. Performativity is the actional state of a performance, also understood as virtual reality.

Os Estudos da Performance, pouco a pouco, vêm ganhando adeptos e expandindo seu campo de atuação entre nós. Iniciados por Richard Schechner a partir dos anos de 1970, foram sendo lentamente urdidos e aplicados, em grande parte como consequência de seu trabalho como encenador à frente do The Performance Group, suas aulas na Universidade de Nova York e pesquisas realizadas em diversos locais dos EUA, da África e da Ásia.

Após conhecer polêmicas com alguns teóricos que defendiam a performance art, seu caráter inédito e proposta de fazer algo transgressivo em relação ao tecido cultural onde emergia, o encenador, ao contrário, defendia o viés repetitivo, de retomada e restauração que a performance detêm, pouco a pouco as coisas foram entrando nos eixos. Ou seja, o entendimento contemporâneo da performance a situa como uma oscilação entre a inovação e a conservação.

\footnotetext{
${ }^{1}$ Edelcio Mostaço é pesquisador do CNPq, professor de Estética Teatral na graduação e no Programa de PósGraduação em Teatro da UDESC.
} 
O termo performance traz embutida uma série de significações, sendo por isso tomado como um "termo chave", ou seja, dá acesso a um sem número de acepções - até mesmo contraditórias entre si -, marcando-se pelo seu caráter lábil e escorregadio. Diante desse quadro os Estudos da Performance apontam alguns rumos e criam contextos onde o termo possa circular e ser referido, evitando seu transbordamento e alcance. Procurarei aqui circunscrever tais sentidos e usos, seguindo em grandes linhas alguns de seus mais férteis teóricos (BIAL: 2008).

Como ocorre com outros termos problemáticos, é melhor evitar uma definição e até mesmo uma tradução, dadas as peculiaridades da língua inglesa onde ele se origina; procurando-se, antes, traçar seu contexto e campo de manifestação. Inicialmente, pode-se afirmar que a performance é tanto um processo quanto um produto; ou seja, é algo que é feito, produzido, ocorre, emerge, cresce dentro e através de um processo, sendo também o que dele resta, seja enquanto algo feito, construído, materializado ou enquanto memória e recordação.

Assim, a performance é também produtiva e propositiva, uma vez que causa, produz, cria tanto ela mesma quanto o outro. Tal produtividade emprega frequentemente a linguagem como função, uso ou intenção, visando certos objetivos, tais como: investigar intelectualmente um fenômeno; jogar afetivamente com algo; recuperar alguma memória cultural; introduzir um comentário social; propor uma ação prática ou aferir uma dimensão psicológica. Destacar os efeitos provocados por algo, portanto, (uma história, uma identidade, um artifício artístico, a etnografia de um comportamento etc.) igualmente são performances, perceptíveis também quando se estrutura algo ou se constitui um sentido.

Num terceiro plano, a performance é tanto tradicional quanto transformadora, pois sempre refere um modo de formar, compor, atuar, ver, acreditar. Tais processos podem ser empregados quer para manter e conservar o status quo quer para alterá-lo e reorientá-lo, daí o caráter ambivalente que a reveste. Performances criticamente efetivadas (tais como a performance art, a live art, a land art, a action painting etc.), contudo, privilegiam os estados de trânsito, o viés transgressivo dos indivíduos, os formatos móveis e as violações de limites como plataforma de atuação, realçando seu caráter transformativo, de labilidade frente à estabilidade (JACKSON: 2004).

Essas três dimensões circunscrevem a performance como um locus de transformação e um verdadeiro paradigma de resistência cultural, uma vez que abarca o espaço, 
a corporificação, toda a coletividade, pois se a um tempo forja a communitas pode também atuar para desestruturá-la. Ela é a aparência site specific de um local - quando nos encontramos em ambientes em rede - e depende muito das discriminações que o indivíduo pode fazer em relação às suas percepções ou desejos, desde que treinado através dela (BELL: 2008).

Ao contrário do que alguns afirmam, tentando apontar na performance suas oscilações, fragilidades e falta de especificidade, gostaria de ressaltar três aspectos exponenciais que desmentem tais críticos: seu caráter constitutivo, seu âmbito epistêmico e seu olhar crítico.

A performance é constitutiva porque forma, institui, corporifica e organiza coisas e processos, culturas, identidades, estados móveis ou permanentes, valendo-se de processos legais, morais e sagrados; ou, ainda, manuais, tecnológicos e digitais, em cada instância e em cada situação. Se toda cultura é permeada pelos processos performáticos, podemos flagrá-los na constituição do sexo, da raça, do gênero, na biopolítica; bem como na criação de zonas de segurança, de controle financeiro, limites e fronteiras advindas após processos bélicos ou diplomáticos; encontrando-se ainda na base de todos os jogos, divertimentos, comemorações e celebrações.

Por enveredar por caminhos que desfazem a dicotomia corpo/mente, a performance é epistêmica. Não apenas recusa a clássica assertiva "penso, logo existo" como elege outros objetos como focos de problematização, contribuindo para alargar as teorias do conhecimento assentadas sobre os sentidos, as percepções e os estudos da linguagem. Partindo do pressuposto de que tanto o real quanto o sujeito são socialmente construídos, ela elegeu o dialogismo como lógica operacional para o estudo da experiência, tornando as refrações interacionistas seu campo preferencial de pesquisa. Também manifesta correlações com a fenomenologia, com o desconstrucionismo, com a etnografia perspectivista, privilegiando certos processos humanos como a intimidade, o envolvimento e o aqui-e-agora, pois são eles que revelam, em modo agudo, sua operosidade e manifestação.

Diante desse quadro, talvez seja redundante afirmar que sua atuação almeja a crítica dos sistemas instituídos; mas tal dimensão merece destaque quando sabemos que entre seus objetivos está a identificação das forças sociais em ação, suas ambiguidades e contradições, para além da aparência e do efêmero; guiando juízos e avaliações sobre os contentamentos ou descontentamentos que nos afligem; dirigindo 
a investigação epistêmica em modo valorativo quanto às interpretações dos símbolos, valores, costumes, códigos etc., assim como reconhecendo os vetores atuantes nas relações de força e magnitude do poder. Ela permite construir um olhar e inspira atos de justiça, ao nomear e analisar aquilo que está ou permanece apenas como intuição no plano dos sentimentos. Isso tudo é reflexão, apontando para seu caráter estético e político, demandando a instituição de novos sentidos.

Para explorar algumas dessas dimensões, vou me deter em quatro conceitos operados pelos Estudos da Performance, visando contextualizá-los e situa-los em seus universos de ocorrências.

\section{Drama Social}

Foi a Escola de Palo Alto, Califórnia, quem desenvolveu, entre os anos de 1940 e 1950, as formulações em torno do drama social ou dramatismo. Intelectuais como Gregory Bateson, Edward T. Hall, Erwin Goffman, entre outros, ocuparam-se com o que ocorre no interior das classes sociais, investigando suas ambiguidades, grupos e subgrupos que as conformam, além de seus ritos, valores e sistemas de legitimação. Especial ênfase foi dispensada aos fenômenos das comunicações e da transmissão de linguagens. A teoria teatral foi utilizada como metáfora para embasar esse novo processo analítico, e termos como "ator", "conflito", "cena", "desenlace” ou "escuta" passam a circular nessas investigações (GEERTZ: 2008).

O dramatismo procurou rebater duas posições anteriores: a que tomava a sociedade como máquina e os indivíduos como dentes de uma engrenagem (positivista, mecanicista); bem como a que tomava a sociedade como "natural," observando em sua dinâmica a ação de "instintos" ou "forças atávicas" (até o final do século XIX) ou, mais recentemente, as "leis biológicas", "bioquímicas" ou "comportamentais" controlando-a. Razão pela qual o dramatismo social retoma o vocabulário advindo do campo teatral para destacar o caráter dialógico da cultura, uma vez que o homem é linguagem e vive na linguagem.

Levar a analogia dramática a sério significa levar a investigação além dessas ironias comuns, e chegar a meios de expressão que façam da vida coletiva algo que valha a pena, sustenta Geertz (2008: 44). O modelo teatral emergiu a partir de um paradigma largamente anteriormente utilizado, ele próprio uma expressão da narratividade e do perfil ideológico que conforma as estruturas sociais. Duas tendências se manifestaram a partir dos estudos iniciais da Escola: a dramatista (que privilegia os 
procedimentos retóricos do drama como base constitutiva, no campo estético notadamente desenvolvido por Kenneth Burke), e a ritual (que toma os dramas sociais enquanto variações rituais, sacras ou profanas).

Victor Turner foi o criador da segunda tendência. Professor de Richard Schechner na universidade, influiu diretamente para a criação dos Estudos da Performance, a eles se associando numa etapa posterior, através de títulos hoje clássicos nesses domínios. Turner privilegiou não apenas a linguagem como também os conflitos sociais como fonte de seus estudos, surpreendendo nas sociedades seu aspecto processual, o que o levou a tomar os ritos sociais como base operativa par excellence enquanto interesse investigativo (1987).

Segundo ele, os dramas sociais e seus ritos se dividem em quatro estágios: a) ruptura - momento em que uma ação se contrapõe, rejeita ou deixa de cumprir uma norma crucial anterior, desencadeando uma crise societária. Tal ação pode ser um crime, a violação de algum símbolo instituído, a profanação de um interdito, sempre em caráter público e deliberado, tomado como uma transgressão grave pelos demais, efetivada em nome próprio ou de outros. Na sequência temos a b) crise - se não há reparo para a ruptura, seu aprofundamento leva à crise, uma escalada dos efeitos da ruptura. É um momento de suspense e de definição de partidos, uma vez que não há possibilidade de neutralidade. Cada crise possui seu momento liminar, mesmo quando não é um límen o objeto da ruptura, exigindo a tomada de posição dos indivíduos. O terceiro momento é c) a ação corretiva - a tentativa de limitar ou circunscrever os efeitos da crise, através de negociações, arbitragens ou mediações, sempre ocasiões de performances públicas. Nas sociedades contemporâneas tal momento pode ser a transferência da ação de uma corte menor para uma Corte Suprema, comportando seus momentos betwixt and between. A última forma é a d) regeneração - quando há o reconhecimento e a legitimação da ruptura que iniciou todo o processo, implicando em novas configurações sociais. Quando do rompimento entre tribos, pode acarretar o afastamento de uma parte dela ou ao banimento. Para o observador, esta é a fase privilegiada, uma vez que permite a reconstituição de todo o processo, permitindo a análise das implicações existentes (1974).

Esse modelo operativo permitiu a Turner investigar alguns ritos de passagem entre os Ndembu, tribo do noroeste africano; a Revolução Mexicana de Independência em 1810, nela enfatizando a participação do padre Miguel Hidalgo; as peregrinações, 
tanto ocidentais quanto orientais; assim como o candomblé e o carnaval brasileiros, entre outros objetos que o ocuparam.

\section{Liminaridade}

Foi Arnold van Gennep (2011) quem cunhou o conceito de liminaridade, e Turner dele se apropriou para expandi-lo e alarga-lo (1982 e 1987). Em sua acepção primitiva, Gennep o empregou para descrever o estado de um indivíduo ao participar de um rito de passagem. O sentido latino primitivo da palavra (limen) remetia à sua acepção de margem sagrada e especial, adequado para contextualizar pessoas, tempos e lugares envolvidos com forças sobre-humanas.

Turner tomou a liminaridade num sentido maior, empregando-a para situar tudo o que é/está betwixt and between - entre, em transição, no limiar, em condição passageira - no âmbito social, para além dos ritos de passagem, caracterizando estados transitórios ou transitivos que acometem os indivíduos. Nesse ambiente, tais indivíduos são "marginais", isto é, encontram-se numa condição inter-estrutural, quando entendemos que toda sociedade articula e vive dentro de uma estrutura, quando pensados os quadros estáveis que a compõem e nela atuam. Complementarmente a essa grande configuração, é preciso lembrar que entre o útero materno e a sepultura - os únicos lugares fixos que um indivíduo efetivamente conhece em sua existência -, um ser humano está sempre em trânsito, entrando e saindo de ritos sociais os mais diversos (nascimento, puberdade, casamento, trabalho, morte etc.), todos eles aquinhoados com alguma parcela de liminaridade.

Esta situação muito ampla e difusa conformando a liminaridade, contudo, deve ser restringida para que suas propriedades sejam mais bem verificadas. Nessa acepção menor, pessoas liminares são aquelas que estão passando por algum rito social de mais curta duração, mais especificamente de iniciação, entronização, coroação, graduação, sagração ou assemelhados. Nessas situações, tais pessoas não são nada nem possuem nada, no sentido em que ficam momentaneamente suspensas enquanto dura o rito, neófitos infra-humanos. Trata-se de um status ambíguo e ambivalente, geralmente percebido como perigoso ou diferenciado, em função do trânsito e do fluxo de forças e poderes que está se operando. Em quase todos esses ritos, os noviços ficam nus ou sumariamente vestidos, têm os cabelos cortados, comem e bebem frugalmente, passam por processos de purificação ou desintoxicação, condição indispensável que devem 
atravessar para atingir o novo estado. Razão pela qual a liminaridade alcança também o tempo (o período ritual) e o espaço (o local) de tais ritos, geralmente preparados anteriormente através de limpeza, exorcismo ou benzedura (TURNER: 2005 e 2008).

Ritos de iniciação como a efebia grega, a entrada num terreiro de santo, na universidade, numa seita, numa sociedade oculta ou secreta, ilustram perfeitamente os passos dessas cerimônias. Mas a liminaridade pode também ser observada sob outros formatos: a rainha Elizabeth II mandou o príncipe Charles fazer uma escola militar na Austrália, onde passou todas as vicissitudes que qualquer simples soldado ou cidadão experimenta. Nem todos os ritos sociais apresentam caráter solene e cerimonioso, assim como muitos deles já perderam sua configuração "séria"; como o Carnaval ou o Mardi Gras , festas onde a liminaridade mostra-se mais difusa e são as ruas e praças que os albergam, sendo público e não-separado o espaço onde ocorrem.

\section{Communitas}

Victor Turner emprega esse termo diretamente em latim para distingui-lo da palavra "comunidade", substantivo em português do qual é proveniente, mas que adquiriu acepções e sentidos que não lhe interessam adentrar. Ele foi inicialmente mobilizado por Martin Buber na obra Eu e Tu, um exercício dialógico de matriz hebraica. Communitas "é o sentido de divisão e intimidade que se desenvolve entre pessoas que passam pela experiência em comum da liminaridade", conforme fixou Edith Turner em sua Enciclopédia de Ritos Religiosos (2005). Ela é "o presente do encontro", grifa a autora, completando que nela "há algo mágico".

Em diversas obras Victor Turner abordou a communitas, o que nos permite observar o rol de sua abrangência e a força de sua emanação, sendo o comum o sentido forte que faz fulgurar. Como sentimento compartilhado, a communitas caracteriza certo modo de reconhecimento entre pares, verificável através de costumes, linguagem oral ou gestual, eleição de símbolos e emblemas, gíria ou termos de uso restrito, símbolos, condutas ou know how específicos. Ela advém com uma condição ou estado, durando o tempo em que dura essa condição ou estado, podendo levar anos ou poucos minutos, na direta proporção da liminaridade da situação do grupo (1987).

Ela é normativa (modaliza o sentimento que nós construímos), exigindo e imantando lealdade e espírito de sacrifício em prol do grupo. Razão pela qual a communitas se instala em certos ambientes (celas de cadeia, comunidades ermas ou apartadas, 
favelas, periferias ou subúrbios, templos e locais de reclusão etc.), em certos circuitos sociais (drogados, homossexuais, torcidas organizadas, clubes, militares, movimentos sociais, Occupe Wall Street etc.), bem como em certas ocasiões propícias (resistência ao invasor, ativistas que tomam um prédio público, acampamentos para shows, greve de fome etc.), podendo instalar-se também entre músicos de uma jam session, atores de um espetáculo, dançarinos, skatistas, leitores de uma obra de sucesso como $O$ Senhor dos Anéis ou Harry Potter etc.).

Portanto, ela é vivencial, implicando na horizontalidade das relações grupais antes dadas, rebaixando as hierarquias e diferenças num sentimento em comum, onde o self torna-se ajustado a essa condição. Celas de cadeia, presos de um campo de concentração, uma classe social estigmatizada (como na Índia), ilustram bem essa condição de heterogeneidade quanto à origem familiar ou financeira, rebaixadas e niveladas quando submetidas a um mesmo e superior controle e autoridade.

Para a coesão do grupo, é importante o sentido em comum, a unidade de propósitos, a comunicação entre os membros, quando a linguagem adquire o formato de um idioleto e cada qual "pode ler a mente do outro", sabendo qual o próximo passo, como grifa Edith Turner (2005). Esse último aspecto é bem verificável nos desempenhos artísticos (música, dança, teatro, canto coral, mas também em grupos de alpinistas, evangélicos, peregrinos etc.), quando todos se mostram sintonizados, concentrados e em estado de alerta para com o conjunto do evento. Nessa acepção a communitas é espontânea, obedecendo a leis próprias e negando interferências externas, obtendo uma divisão no fluxo das ações e desejos em relação às tarefas em comum.

Pelo conjunto dessas características, a communitas sempre encoraja a crítica ao sistema (nós contra eles, eles são os outros) e às instituições (a polícia, a repressão, a caretice, a norma), uma vez que se desenvolve nos interstícios das estruturas sociais, em situações de liminaridade, nos períodos de mudança de status, na condição de marginalidade (real ou figurada), na situação rebaixada de inferioridade. Resumindo essa multiplicidade de aspectos e a necessidade de identificação que percorre os diversos estratos sociais, Liz Locke afirma: "os não atletas, os leitores, os músicos, os skatistas, os jogadores, os geeks, os metaleiros, os ravers, os da pesada, os internautas inveterados, os desajustados, os refugiados - nós encontramos o modo de criar communitas" (apud BELL, 2008: 135).

Como ela é flexível, instável e mutante, Victor Turner alerta para seus limites: 
a grande dificuldade é manter essa intuição viva, sendo que drogados regulares não o fazem, uniões sexuais regulares não o fazem, imersões constantes na grande literatura não o fazem, e a reclusão da iniciação cedo ou tarde deve caminhar para um fim. É quando encontramos então o paradoxo de que a experiência da communitas torna-se a memória da communitas... (1982: 47).

\section{Performatividade}

Um dos mais originais conceitos operados pelos Estudos da Performance, a performatividade foi pinçada por Richard Schechner dos estudos de J. L. Austin consagrados à linguagem. Na obra How to do things with words, o filósofo investigou situações nas quais a linguagem não apenas exprime ou refere coisas, mas efetivamente produz coisas, seres, estados, condutas, como os casamentos, testemunhos, batizados, registros, sagrações, etc., ao empregar frases como "eu sou", "vou fazer," "prometo cumprir", o "sim" de um matrimônio, e outras assemelhadas. Ou seja, são situações onde falar é agir, ou, dito de outro modo, o agir é o próprio falar, o que comporta também as manifestações íntimas silenciosas ou apenas gestuais.

Num outro sentido, a performatividade refere o próprio fazer da performance, ou seja, indica o know-how nela empregado, aquilo que a conforma ser o que é. Por isso ela é um substantivo (indica um processo ou um produto) e também um advérbio de modo (indica a propriedade designada "como se," um "ao modo de" associado àquele produto ou processo que, em si mesmo, pode não ser uma performance). No primeiro caso, refere qualquer tipo de retomada ou restauração (um professor explicando o teorema de Euclides, ou seja, retomando algo que foi criado há muito tempo; um conferencista usando um exemplo para ilustrar um raciocínio; uma personagem teatral mostrando como foi que entrou na casa de outro, etc.). No segundo caso, o termo refere uma condição ou estado ("Parece que Maria correu 20 quilômetros, está com a língua de fora”; "João me disse que ela é uma máquina na cama”; "Não... não, ele não é um arrogante, apenas está tentando dizer que ficou triste com sua decisão", etc). Mas, há ainda uma terceira acepção, aquela advinda de seu uso figurado ou metafórico, como são as demonstrações do oscilante quadro da Bolsa de Valores, os mapas com as variações térmicas do tempo, o quadro com as mãos do alfabeto dos surdos-mudos, etc.

Diante da miríade de situações nas quais tais processos ocorrem, Austin separou aqueles em que, dadas as circunstâncias, esse ato/gesto deve ser encarado com suspeita, como são os constrangimentos, as ameaças, as violações e as simulações, 
especialmente o teatro. No teatro, dado seu caráter fictício, as palavras ditas pelos atores não devem ser a eles imputadas, mas às personagens. Essas manifestações problemáticas da linguagem configuram um uso ad judice da performatividade.

Há aqui, portanto, certa parcela de fingimento, falta de verdade ou desajuste, uma vez que não podem, stricto sensu, serem tomadas como verídicas. Foi exatamente essa condição que levou Schechner (2002) a privilegiar a performatividade como um dos centros irradiadores dos Estudos da Performance, onde contínuos processos de retomadas e restaurações desajustadas são verificáveis, notadamente quando se trata das construções de gênero, raça e sexo. Mas também podem ser tomados como performativos, no ambiente da pós-modernidade, as dimensões políticas, econômicas, sociais e a própria construção da realidade, traços já apontados por Paul de Man, Jean-François Lyotard ou Jacques Derrida em estudos que retomaram as categorias de Austin.

Um americano pode hoje assistir pela TV a guerra se desenrolando no Iraque, emocionando-se vivamente com seus garotos que bravamente lutam pela democracia e em nome dos mais arraigados valores do povo estadunidense. O que ele não suspeita é que a cena foi cuidadosamente "produzida" ou "montada" pelos estrategistas do exército e, posteriormente, editada pelos telejornais e redes de TV, com o objetivo de causar certos efeitos de convencimento e reafirmação ideológica. Ou seja, embora pareça real, a cena é uma encenação, é um efeito de real, portanto performativa. A luta pelos valores esconde as verdadeiras intenções governamentais, ligadas ao desenvolvimento da indústria bélica, astronômicos gastos empregados com a segurança, a criação de um clima de permanente ameaça sobre a democracia, justificando assim o uso político do orçamento público quer no plano interno (política de austeridade fiscal) quer externo, mundial, que conduz os EUA à postura de xerife do Império. É a desconstrução daquela cena de TV que permite avaliar todos os passos empregados em sua arquitetura de linguagem e ideologia.

É essa desconexão linguajeira ou anomia sociológica que pode ser observada na performatividade, onde nem tudo que parece o é de fato. Ou, quando observada mais de perto, evidencia a perda dos referentes semióticos ou a falta de convicção em sua recepção, o que a desloca como um novo formato de metalinguagem. Empregada pelas práticas artísticas em modo crescente (desde John Cage a Alan Kaprow, desde Pirandello a Jean-Luc Lagarce), a TV, o cinema, o teatro e a dança - bem como as 
infinitas outras formas de representação advindas com a revolução digital -, a performatividade hoje ocupa função central em tudo aquilo que envolve as representações, reais, simbólicas ou virtuais. Ou seja, vivemos na sociedade do espetáculo, como destacou Guy Débord, na era dos reality-shows simulando a vida e o real.

A virtualidade tornou-se o coração da expressividade contemporânea, levando os artistas a assumirem a postura de novos alquimistas, bem como o fundamento de uma série de outras práticas referidas como hibridizações, mestiçagens, clonagens, realidade virtual, imersão na matrix, que definitivamente eliminaram a distinção entre original e cópia. O que só faz aumentar a dimensão da performance em seus próprios fundamentos e ontologia, ocupando papel decisivo na seara aberta com os estudos culturais (SCHECHNER: 2007).

\section{Referências}

BELL, Elizabeth. Theories of performance. Los Angeles. Sage Publications: 2008.

BIAL, Henry. The performance studies reader. London. Routledge: 2008.

GEERTZ, Clifford. "Mistura de gêneros: a reconfiguração do pensamento social", in O Saber Local. Petrópolis. Vozes: 2008.

GENNEP, Arnold van. Os ritos de passagem. Petrópolis. Vozes: 2011.

JACKSON, Shannon. Professing performance - theatre in the academy from philology to performativity. Cambridge. University of Cambrige Press: 2004

SCHECHNER, Richard. Performance studies - an introduction. London. Routledge: 2002. "Victor Turner's Last Adventure", in TURNER, Victor. Anthropology of Performance. New York. PAJ Publications: 1987. Performance theory. London. Routledge: 2007.

TURNER, Edith. "Rites of Communitas", in Encyclopedia of Religious, Rites, Rituals, and Festivals, Frank A. Salamone (org), apud BELL, E. Theories of Performance, cit.

TURNER, Victor. O processo ritual - estrutura e antiestrutura. Petrópolis. Vozes: 1974 1982. .From the ritual to theatre - the human seriouness of play. New York. PAJ Publications: The anthropology of performance. New York. PAJ Pubications: 1987. Floresta de Símbolos - aspectos do ritual Ndembu. Niterói. Ed. Universidade Federal Fluminense: 2005.

Dramas, campos e metáforas. Niterói. Ed. Universidade Federal Fluminense: 2008. 